\title{
Saúde e trabalho rural: o caso dos trabalhadores da cultura canavieira na região de Ribeirão Preto, São Paulo, Brasil
}

\author{
Health and work in rural areas: sugar cane \\ plantation workers in Ribeirão Preto, São Paulo, \\ Brazil
}

Neiry Primo Alessi 1

Vera Lucia Navarro 2

1 Departamento de Medicina Social, Faculdade de Medicina de Ribeirão Preto, Universidade de São Paulo. Av. Bandeirantes 3900, Ribeirão Preto, SP 14049-900, Brasil. 2 Faculdade de Filosofia, Ciências e Letras de Ribeirão Preto, Universidade de São Paulo. Av. Bandeirantes 3900 Ribeirão Preto, SP 14049-900, Brasil.

\begin{abstract}
This study is based on an understanding of health and rural labor as a social process related to the characteristics of the agrarian issue in Brazilian society, focusing on sugar cane cutters in northeastern São Paulo State, Brazil, and attempting to identify patterns of attrition and reproduction in such labor. Based on direct observations, interviews with laborers and other agents involved in production, and a related bibliographical review, the analysis points to daily exposure of cane cutters to physical, chemical, and biological hazards resulting in various diseases, traumas, and accidents: dermatitis, conjunctivitis, dehydration, cramps, dyspnea, respiratory infections, high blood pressure, and wounds, besides aggravating the biopsychic burden underlying attrition patterns showing up in the spinal column, chest, head, and lumbar pains, nervous breakdowns, and other kinds of psychosomatic manifestations. This study of the work process pointed up its unhealthy working conditions and helped provide an overview of the conditions and means by which capital asserts itself in Brazil - in its self-reproduction process - especially in the agro-industrial sector.
\end{abstract}

Key words Worker's Health; Rural Workers; Occupational Accidents; Rural Health

Resumo O presente trabalho destaca a análise do processo de trabalho do cortador da cana-deaçúcar na região nordeste do Estado de São Paulo, Brasil, buscando apreender os seus padrões de desgaste-reprodução. Com base em observações diretas, entrevistas com trabalhadores e outros agentes envolvidos na produção e consultas à bibliografia pertinente, a análise desenvolvida revela a exposição diária dos cortadores de cana a cargas físicas, químicas e biológicas, que se traduzem em uma série de doenças, traumas, ou acidentes a elas relacionadas: dermatites, conjuntivites, desidratação, cãimbras, dispnéias, infecções respiratórias, alterações da pressão arterial, ferimentos e outros acidentes; destacando-se também cargas biopsíquicas configurando padrões de desgaste manifestos através de dores na coluna vertebral, dores torácicas, lombares, de cabeça e tensão nervosa e outros tipos de manifestações psicossomáticas. O estudo desse processo de trabalho permitiu não apenas detectar as condições insalubres do trabalho, mas também delinear um quadro das condições e meios de que o capital se vale, no Brasil, no seu processo de auto-reprodução, particularmente, no setor agro-industrial.

Palavras-chave Saúde do Trabalhador; Trabalhadores Rurais; Acidentes do Trabalho; Saúde Rural 


\section{Introdução}

Abordar a temática Saúde e Trabalho Rural, além dos desafios que encerra, requer que se façam algumas considerações de caráter geral e específico para, posteriormente, explicitar os recortes que serão realizados, derivados da complexidade do objeto que se manifesta, inicialmente, na diversidade de processos de trabalho a que estão submetidas as quase $15 \mathrm{mi}$ lhões de pessoas que desempenham algum tipo de trabalho agrícola e, na sua maioria, na condição de empregados. Há que se destacar também a pertinência da temática que se traduz na importância do setor primário no processo de desenvolvimento econômico-social de nossa sociedade quando se considera que, em 1991, do total de 147.053.900 habitantes, 62.100 .499 eram pessoas com 10 anos ou mais, ocupadas, das quais $23 \%$ desempenhando algum tipo de atividade no ramo de atividades agrícolas, enquanto que $21 \%$ e $56 \%$ nos ramos de atividades industriais e de prestação de serviços, respectivamente (IBGE, 1993).

Em termos gerais, é necessário destacar a expressiva produção científica sobre Saúde e Trabalho, principalmente a partir dos anos oitenta, objetivando o desvendamento das articulações processo saúde-enfermidade e processo laboral no contexto de formações econômico-sociais específicas.

Cabe ressaltar que apesar de a maioria dessas análises considerarem os seus objetos no quadro da heterogeneidade estrutural que caracteriza o processo de desenvolvimento econômico-social de cada formação econômicosocial de referência, apontando para o aprofundamento de contradições endógenas e exógenas que se refletem, entre outros aspectos, na sujeição da maioria da população a precárias condições de existência social, os seus objetos referem-se principalmente a processos de trabalho dos setores secundário e terciário (principalmente aqueles das indústrias de ponta e do setor prestador de serviços de consumo coletivo) e, desse modo, pouco enfocando processos de trabalho do setor primário da economia.

Um outro traço constitutivo dessas análises reside em conceber os seus objetos de análise como processos sociais, o que pressupõe que da compreensão do processo de produção, reprodução e transformação da existência social é que derivam as explicações dos porquês do homem ser ou não acometido por ciclos biopsíquicos de determinadas enfermidades (Laurell \& Noriega, 1989; Cohn \& Marsiglia, 1993).

Diferentemente da visão hegemônica na área da saúde, que concebe a doença através de manifestações biológicas individuais, o pensamento médico social latino-americano tem como ponto de partida que o corpo humano é um conjunto de potencialidades (físicas e psíquicas) que possibilitam ao homem, via processos de adaptação, elaborar respostas tendo em vista a satisfação de necessidades das quais depende a sua sobrevivência. Entretanto, as formas de adaptação do corpo humano não se restringem ao individual. Em sendo o homem um ser social, elas têm também caráter coletivo e emergem da maneira como os grupos sociais produzem e reproduzem sua existência material e imaterial em momentos históricos determinados.

Em outras palavras, o objeto saúde-enfermidade é entendido como as formas históricas que os processos bio-psíquicos assumem em momentos específicos do processo de desenvolvimento de sociedades concretas, tornando possível apreender o nexo bio-psíquico do processo saúde-enfermidade que se expressa nos grupos sociais através de quadros de desgaste reconhecidos ou não como patológicos pelo conhecimento hegemônico na área da saúde.

A unidade de análise desse modelo é a categoria trabalho que, sob o modo de produção capitalista, determina uma das formas de relacionamento social, ou seja, aquela que coloca em interação empregados e empregadores. Os papéis sociais desempenhados por esses agentes são opostos e complementares entre si e estão definidos pela posição que ocupam no processo da produção: proprietários e não proprietários dos meios de produção (Alessi \& Scopinho, 1994). Isto é, a categoria trabalho é entendida como estando "atavicamente vinculada aos padrões das relações sociais, econômicas e políticas vigentes na sociedade mais ampla" (Fischer, 1985).

O modo de produção capitalista é um processo de produção de mercadoria e de maisvalia, através do uso de objetos, instrumentos e da força de trabalho assalariada, materializada esta sob a forma de trabalho concreto. $\mathrm{O}$ momento da produção de mais-valia (processo de valorização) é um dos momentos dominantes do capitalismo e consiste na reprodução ampliada do capital. O momento da produção de bens (processo de produção) é aquele através do qual se realizam processos de trabalho concretos (corpo humano, meios e instrumentos de trabalho interagindo em uma atividade orientada para um fim) os quais, na verdade, constituem a materialização do processo de valorização do capital. Toda e qualquer referência a processos de trabalho significa considerar modos concretos de trabalhar que, por 
sua vez, contém, implicitamente, modos concretos de consumo e de desgaste da força de trabalho (Alessi \& Scopinho, 1994).

Desvendar processos de trabalho e padrões de desgaste-reprodução, tendo como ponto de partida modos concretos de trabalhar, requer que se apreendam as necessárias articulações com o momento do processo de valorização, condição fundamental de sua realização. A análise de processos de trabalho específicos, considerados através de sua base técnica, da divisão e da organização do trabalho, é que possibilita apreender os seus padrões de desgaste-reprodução que se manifestam através de formas concretas de consumo, desgaste e grau de controle da força de trabalho no momento da produção (Laurell \& Marquez, 1983; Laurell \& Noriega, 1989).

Neste referencial, o conceito de carga laboral é a mediação central para a compreensão do objeto saúde-enfermidade em suas relações com processos de trabalho específicos.

Concebidas como o conjunto de elementos externos (físicos, químicos, mecânicos e biológicos) como internos (fisiológicos e psíquicos) presentes nos ambientes e nas condições de trabalho que interagem entre si e com o homem, as cargas laborais podem gerar ou não padrões de desgaste específicos. Em outras palavras, nos elementos constitutivos das cargas laborais de processos de trabalho é que reside a origem do desgaste que, ao referir-se às potencialidades humanas historicamente determinadas, pode significar perda ou não de capacidades biopsíquicas no processo de trabalho (Laurell \& Noriega, 1989).

Como considerações de caráter específico coloca-se a questão agrária na sociedade brasileira.

A partir da década de sessenta (60), intensificam-se as transformações no meio rural, repercutindo negativamente nas condições de vida, trabalho e na saúde do trabalhador rural.

Essas transformações têm-se processado no nível da produção em si e também no das relações de trabalho, resultando em aumento e diversificação da produção agrícola e também na recriação de antigas e na emergência de novas formas de organização do trabalho.

Em relação ao volume da produção, este passou a ser determinado pela incorporação de novas áreas ainda não cultivadas (o denominado processo de expansão da "fronteira agrícola”), pela substituição de lavouras com a introdução de novas espécies de cultivo, a generalização do uso de insumos, máquinas agrícolas, crescente uso das descobertas da engenharia genética e pressupondo a crescente concentração da propriedade fundiária e da renda.

No tocante às relações de trabalho, presencia-se o acirramento do processo de expulsão dos antigos colonos das fazendas, tendo como um de seus resultados a gradativa substituição das relações de trabalho como o colonato, os moradores, a meação, a parceria e a recriação, em outros momentos, destas antigas relações de trabalho e de formas escravistas (Martins, 1995) concomitante à propagação do trabalho assalariado.

Esse processo não ocorreu de modo linear, mas apresentando nuances diversas derivadas do tipo de cultura, sua localização espacial, volume de capital investido e das políticas governamentais de fomentos e subsídios, entre outras.

Transformam-se os processos de trabalho manifestamente subordinados ao capital. É o caso de culturas comerciais como, por exemplo, o café, cana-de-açúcar, soja e milho que apesar de mantidas praticamente constantes as condições técnicas de sua produção, modificamse os seus processos de trabalho que, sob a dependência do capital, rompem com as relações de trabalho não estritamente capitalistas.

Entretanto, parte dos empresários agrícolas impedidos ainda de subsumirem realmente a produção agrícola ao domínio completo do capital, mas estando regidos pela lei do lucro, recorrem amplamente ao uso dos processos de prolongamento da jornada de trabalho e de intensificação do seu ritmo, o que possibilita apropriarem-se de um mais-trabalho absoluto (Gonzales \& Bastos, 1982).

Ianni (1984), ao analisar a agroindústria açucareira, afirma que, na agricultura, processa-se a exploração combinada de mais-valia absoluta com mais-valia relativa.

Desse modo, o trabalho no campo, sob a égide das relações capitalistas de produção, passa a ser marcado pela extensão da jornada de trabalho, intensificação do seu ritmo, pagamento por produção, decréscimo real do valor dos salários e descumprimento de direitos trabalhistas.

Submetido a essas novas condições o trabalhador rural, para usar uma expressão de Laurell \& Noriega (1987), rompe com o tempo natural e passa a ser regido pelo tempo do capital ou, pelo tempo que é valor.

As repercussões dessas transformações nas condições de existência social dos trabalhadores rurais, particularmente nas de saúde, são extremamente graves.

A expansão do capitalismo na agricultura, ao provocar migrações expressivas do campo 
para a cidade, determinou alterações nos padrões de morbi-mortalidade da população do país.

Algumas destas alterações traduzem-se na propagação de doenças transmissíveis por todo o país, como a esquistossomose e a doença de chagas, anteriormente concentradas em regiões circunscritas, que encontram terreno fértil à sua extensão devido às condições precárias de saneamento básico em todo o país e à maior vulnerabilidade propiciada pela desnutrição, presente em parcela expressiva da população (Possas \& Trapé, 1983; Litvoc, 1985; Dias, 1992).

O trabalhador rural ao ser expulso do campo passa a residir nas periferias das cidades, encontrando no mercado de trabalho a possibilidade de ofertar a sua força de trabalho a grandes empreendimentos agrícolas. Às suas condições de saúde já debilitadas acrescem-se novos padrões de desgaste que se traduzem em envelhecimento precoce, morte prematura, doenças cardiovasculares, degenerativas, mentais, entre outras (Possas, 1989; Barreto \& Carmo, 1994).

Essas características do setor primário e suas repercussões na saúde do trabalhador rural, sumariamente colocadas, apontam para a necessidade de recortar a temática Saúde e Trabalho Rural.

Apesar de similaridades presentes numa diversidade de processos de trabalho rural que se manifestam em cargas laborais e padrões de desgaste constitutivos dos ambientes e das condições de trabalho (como o meio de transporte que coloca em risco de vida milhares de trabalhadores, a exposição a agrotóxicos e intoxicação por eles, mudanças de temperatura, acidentes com instrumentos de trabalho, etc.) é, no entanto, a referência a processos de trabalho específicos que possibilita apreender suas especificidades derivadas, principalmente, de seus modos de divisão, organização e da tecnologia empregada (Paixão, 1994; Cohn \& Marsiglia, 1993).

Explicitadas algumas razões da necessidade de recortar a temática, inicialmente será especificado o percurso metodológico utilizado que fundamentou a reconstrução do processo de trabalho do cortador de cana-de-açúcar, da região de Ribeirão Preto - S.P., cuja análise buscou apreender os padrões de desgaste dessa força de trabalho, com isto, objetivando contribuir para elucidar alguns aspectos da questão Saúde e Trabalho Rural.

Do ponto de vista metodológico, a análise desenvolvida procurou fundamentar-se na pesquisa-ação (Brandão, 1985) por entender que a reconstrução de processos de trabalho e seus padrões de desgaste-reprodução correspondentes também requerem a participação de trabalhadores na geração de conhecimentos.

Neste sentido foram realizados grupos de discussões e entrevistas abertas com os trabalhadores, nos intervalos de suas jornadas de trabalho, com base em roteiros previamente estabelecidos. Também, foram realizadas, no campo, entrevistas abertas com dirigentes sindicais, empreiteiros de mão-de-obra e observações diretas do processo de trabalho do corte da cana-de-açúcar. Outros recursos utilizados foram a elaboração de documentação fotográfica e filmagem do referido processo de trabalho.

A pesquisa foi realizada nas cidades de Santa Rosa de Viterbo e Pontal, pertencentes à região administrativa de Ribeirão Preto - S.P., atendendo a uma demanda do Sindicato de Trabalhadores Rurais daqueles municípios.

Este percurso metodológico, juntamente com o levantamento da bibliografia pertinente e da consulta aos registros de atendimentos de trabalhadores e das fichas de Comunicação de Acidentes de Trabalho (CAT) existentes nos serviços de saúde dos municípios acima citados, possibilitou identificar os padrões de desgaste - reprodução inerentes ao processo de trabalho do corte da cana-de-açúcar.

Feitas essas considerações, é fundamental, ainda que de maneira breve, contextualizar histórica, social e economicamente a região na qual o cortador de cana-de-açúcar figura como categoria central do processo de geração e acumulação de capital.

\section{A Região de Ribeirão Preto}

A região de Ribeirão Preto é sempre citada como a que apresenta expressivos índices de crescimento econômico quando comparada com outras regiões do interior do Estado de São Paulo, fato este que se popularizou na expressão "Califórnia Brasileira".

Situada na região Nordeste do Estado de São Paulo o seu surgimento data do início do século XVIII com o declínio da mineração e da revolta conhecida por Inconfidência Mineira.

A efetiva ocupação da região consolida-se, a partir de meados do século XIX, com o desenvolvimento da cafeicultura favorecida por condições climáticas, tipo de solo, alto valor do café no mercado internacional, por políticas governamentais de incentivo à produção e imigração italiana, imprimindo outro dinamismo 
às forças produtivas e relações de produção traduzidas, entre outros aspectos, na elevação do preço da terra, concentração da propriedade fundiária e no desenvolvimento do colonato (Ianni, 1984; Semeghini, 1992).

A superprodução e a queda nos preços do café no mercado internacional, anunciando o declínio da cafeicultura, a partir da década de trinta (30), encontrou na região condições objetivas para a sua rápida substituição pela pecuária e a diversificação de culturas (notadamente a cana-de-açúcar, amendoim, algodão, cítricos, milho e soja), produtos esses fornecedores de matérias-primas às agroindústrias que se instalam na região.

Cabe referir que o desenvolvimento regional sempre se processou articulado ao conjunto das transformações político-econômicas nacionais, nutrindo-se de conjunturas econômicas internacionais favoráveis e de políticas nacionais sustentadoras das atividades produtivas, particularmente as do setor agroindustrial (como a regulamentação do preço da cana estabelecida pelo Estatuto da Lavoura Canavieira em 1942; as políticas de incentivos à produção de açúcar pelo Instituto do Açúcar e do Álcool a partir de 1933; a legislação trabalhista definida através do Estatuto do Trabalhador Rural em 1963; a instituição do Programa Nacional do Álcool em 1975, entre outros).

Na região sempre predominaram as atividades do setor primário e num cenário privilegiado das transformações presenciadas na agricultura brasileira.

No setor primário predominam as culturas de cana-de-açúcar e de cítricos representando, na década de oitenta (80), $42 \%$ e $61 \%$, respectivamente, do total da produção do Estado. Cabe ressaltar também que a região produz $40 \%$ do total do açúcar produzido no Estado, sua produção de álcool abastece $32 \%$ da frota nacional e produz $70 \%$ do suco de laranja exportado do Estado de São Paulo. Também é expressiva a produção de soja, amendoim, milho, bovinos e aves (Semeghini, 1992).

Todas essas atividades pressupõem uma estrutura fundiária bastante concentrada, o uso expressivo de mão-de-obra sazonal, garantindo ao setor rentabilidade derivada do fato de a sua produção estar voltada para a oferta de matéria-prima para exportação e para as indústrias alimentícias e, devido ao fato de utilizar, em seus processos produtivos, uma das mais avançadas bases técnicas. Cabe mencionar as agressões sofridas pelo meio ambiente, em nome desse "desenvolvimento", tais como o empobrecimento do solo; desmatamento desregrado de áreas críticas, aumento da po- luição de rios, mananciais com o despejo de resíduos industriais (vinhoto) e agrotóxicos e, também, a poluição da atmosfera produzida com a queima da cana (Marinho \& Krichkoff, 1991; Szmrecsányi, 1994).

A Associação Brasileira de Reforma Agrária estimou, para 1975, a presença de 287.513 trabalhadores volantes no Estado e 87.254 na região de Ribeirão Preto. Onze anos depois, o total no Estado saltou para 370.943 e, na região, em torno de 95.000 trabalhadores volantes (Amstalden \& Costa, 1992).

O setor secundário é bastante expressivo, cujo desenvolvimento está principalmente voltado à produção e manutenção de bens de capital para as agroindústrias e de bens de consumo não duráveis. Destacam-se, em ordem de importância, as indústrias de produtos alimentares, as de transformação de produtos minerais não-metálicos, a metalurgia, de mobiliário e a mecânica, seguida pelas indústrias de vestuário e calçados (Alessi \& Pinheiro, 1987; SEADE, 1988; Semeghini, 1992).

O setor terciário caracteriza-se por uma oferta de serviços bastante diversificada, sendo o município de Ribeirão Preto o pólo que concentra a maioria dessas atividades. Absorvendo em torno de 50\% da PEA regional com forte predomínio do setor prestador de serviços, destacando-se os de alojamento e alimentação, instalação, manutenção, reparação e confecção sob medida. Também é expressivo o setor de comércio de mercadorias dimensionado para atender regionalmente (shopping-centers; hipermercados; revendedoras de veículos automotores importados, etc) e o setor de serviços bancários que aponta o município de Ribeirão Preto como a $6^{\text {a }}$ praça financeira do país (Alessi \& Pinheiro, 1987).

Em relação aos serviços de apoio à população é expressiva na região a presença dos setores educacional e de saúde, tornando o município de Ribeirão Preto como centro de referência regional, estadual, nacional e internacional.

Esse desenvolvimento regional vem se processando num quadro de divisão social do trabalho imprimindo certo grau de especialização nas atividades dos municípios, configurando “... um quadro tipicamente desigual e combinado e a integração entre esses diferentes espaços e especialidades é possibilitada pelo excelente sistema viário disponível. Ampliado e diversificado, sobretudo a partir dos anos oitenta, o sistema viário sustenta ligações intra e inter-regionais" (Scopinho, 1995).

Cabe destacar o dinamismo populacional da região cuja taxa de crescimento na década 
de oitenta (80) superou a do Estado de São Paulo e a do País (SEADE, 1992).

Se, por um lado, conforme referido anteriormente, a região de Ribeirão Preto é conhecida como "Califórnia Brasileira”, a sua riqueza tem sido possibilitada pela intensificação das desigualdades sociais, derivadas que são da concentração da propriedade e da renda em mãos de uma parcela pequena de sua população.

Essas contradições expressam-se com mais intensidade no setor sucroalcooleiro - principal força propulsora do desenvolvimento econômico-regional - que tem como um de seus principais atores sociais “o bóia-fria” que, segundo Graziano da Silva (1981:119), é o resultado da organização da produção sucroalcooleira e, ao mesmo tempo, de sua insuficiência e fraqueza: "da insuficiência do capital em submeter as forças da natureza do ponto de vista técnico; da fraqueza de generalizar sua subordinação, não apenas do ponto de vista formal mas, sobretudo, de uma maneira real e ampla, revolucionando a produção agrícola em todas as suas fases".

\section{O processo de trabalho e os padrões de desgaste e reprodução da força de trabalho empregada no corte da cana-de-açúcar}

É impossível negar o quanto o trabalho do cortador de cana é árduo. É um trabalho que, além de expor o trabalhador a toda sorte de intempéries, como a maioria dos trabalhos rurais, (e aqui é bom lembrar que a temperatura na região em épocas de safra pode atingir quase os $40 \circ \mathrm{C}$, expô-lo ao risco de acidentes com animais peçonhentos, intoxicações por agrotóxicos, entre outros), submete-o a ritmos acelerados na medida em que o ganho, geralmente, dá-se por tarefa realizada.

Podemos dizer que o processo de trabalho ao qual está submetido o cortador de cana-deaçúcar inicia-se a partir do momento em que ele acorda e começa a se preparar para embarcar no caminhão que o levará até a lavoura. Inicialmente deve preparar as refeições que fará durante o dia, vestir-se e providenciar seus instrumentos de trabalho. O final do processo vai se dar com o seu retorno ao lar (casa, alojamento ou pensão) depois de cumprir outras tarefas necessárias à sua reprodução, tais como: alimentação, limpeza da casa, cuidados com o vestuário pessoal e da família, higiene pessoal e cuidados com os instrumentos de trabalho. Só então estará livre para o descanso mínimo necessário para, no dia seguinte, reiniciar a mesma jornada.

O cuidado com o corpo se manifesta já na forma como o trabalhador se prepara para mais um dia de trabalho. Os "equipamentos de proteção individual” (E.P.I.) são, muitas vezes, improvisados pelos próprios trabalhadores. Dos pés à cabeça se faz necessária a proteção. Para isso vale qualquer coisa: roupas sobrepostas, lenços cobrindo o rosto e na cabeça, sob o chapéu ou boné, saias sobrepostas a calças compridas para as mulheres, camisa de mangas compridas, luvas improvisadas com meias, meias ensacando as pernas das calças, tênis ou botas.

Apesar da obrigatoriedade do fornecimento de equipamentos de proteção, como luvas e perneiras (Normas Regulamentadoras Rurais no 4), nem todos os empregadores rurais as observam. E, mesmo quando estes equipamentos estão disponíveis, a inadequação dos mesmos acaba constituindo em outras cargas laborais. Os EPIs que são confeccionados, em geral, com material não adequado ou que não apresentam muitas opções de tamanho, acabam se tornando obstáculos para o trabalhador, antes de ser um instrumento de segurança. $\mathrm{O}$ equipamento que não se adequa ao corpo acaba atrapalhando os movimentos requeridos na operação de corte da cana, prejudicando a produtividade do trabalho.

Outro agravante desse processo de trabalho é que, devido ao ritmo do trabalho, o desgaste desses equipamentos durante a safra é grande. Apesar disto, geralmente, não são fornecidos equipamentos em número suficiente para a reposição no decorrer da safra, ficando sob a responsabilidade do trabalhador a aquisição de novos equipamentos, quando necessário.

As condições adversas do trabalho são visíveis já a partir do tipo de transporte utilizado. Em geral, os cortadores de cana são transportados em caminhões de propriedade dos agenciadores de mão-de-obra (turmeiros ou gatos, como são conhecidos), conduzidos por motoristas inexperientes, algumas vezes inabilitados, em flagrante desrespeito à lei, que prevê que o transporte de "bóias-frias" deva ser feito em ônibus apropriados (cf. art. 190 da Constituição do Estado de São Paulo).

A prática de transportar "bóias-frias" em veículos inapropriados, cuja manutenção raramente é realizada, tem possibilitado a ocorrência de elevado número de acidentes, muitas vezes com graves conseqüências e grande número de mortes de trabalhadores rurais. Segundo Silva et al. (1994), nos últimos 15 anos foi possível levantar o registro de 73 acidentes com 
caminhões de bóias-frias no Estado de São Paulo, em sua maioria ocorridos na região Nordeste, resultando em 269 mortes e 1103 trabalhadores rurais feridos, o que incapacitou para o trabalho grande parte das vítimas, dada a gravidade de tais acidentes.

O trabalhador, ao chegar ainda cedo no canavial, enfrenta, em seu ambiente de trabalho, temperatura elevada. A prática de se queimar a cana antes de seu corte, aquece a terra e, algumas vezes, o calor se conserva até o início da jornada. Este calor se intensifica, no decorrer do dia, pela ação solar. Além disto, o trabalhador, durante a sua jornada de trabalho estará exposto à poeira e à fuligem da cana queimada que impregnam seu rosto, suas mãos e suas roupas. $\mathrm{O}$ ambiente de trabalho é marcado também, em muitos casos, pela inexistência de locais adequados para o depósito de marmitas e garrafas de água e café (que muitas vezes leva à deterioração dos alimentos), pela inexistência de local apropriado para os trabalhadores fazerem suas refeições e pela ausência de instalações sanitárias.

$\mathrm{O}$ fato de o trabalhador ter que levantar-se muito cedo, cumprir uma primeira jornada de trabalho em sua moradia, acrescido do tempo gasto com seu transporte até o local de trabalho, faz com que alguns deles, assim que chegam à lavoura, almocem antes mesmo de iniciarem o trabalho. Outros ainda, realizam tal refeição pouco tempo após o início da jornada e alguns costumam fazê-lo por volta das 11 horas. Tais diferenças apontam para diferentes estratégias adotadas pelos cortadores de cana para prepararem seus corpos para suportarem as agruras de seu trabalho.

Ao longo da jornada o trabalhador se preocupa em repor as energias ao seu organismo bebendo muita água, tomando café e também chupando cana. A prática de chupar cana se, por um lado, repõe a água e sais minerais perdidos pelo organismo, por outro, costuma provocar diarréias, devido ao seu alto teor de sacarose.

O trabalho no corte da cana é organizado em turmas de aproximadamente 30 ou 40 trabalhadores. Apesar de esta organização por turmas, este trabalho envolve procedimentos realizados individualmente pelo mesmo trabalhador, do início ao final do processo, que é dividido nas seguintes operações: corte na base da cana, desponte do palmito e amontoamento.

O corte na base da cana, que consiste na retirada da cana das touceiras, exige do trabalhador uma seqüência ritmada de movimentos corporais. Em geral, com um dos braços, o tra- balhador abraça o maior número possível de colmos de cana. Em seguida, curva-se para a frente e, com o podão seguro por uma de suas mãos, golpeia, com um ou mais movimentos a base dos colmos, o mais próximo possível do solo. Em seguida, faz um movimento de rotação e, ao mesmo tempo, levanta o feixe de cana já cortada, depositando-o em montes atrás de si (denominados "bandeiras"). O espaço entre uma "bandeira" e outra é de 2 metros. É neste espaço que o capataz mede a produção utilizando-se de um instrumento denominado compasso, quantificando quantos metros de cana o trabalhador cortou durante a jornada de trabalho. A transformação da medida em toneladas de cana cortada é feita multiplicandose a metragem por um determinado fator. A atividade do corte se completa com o desponte do palmito (ponteiro).

Cabe ressaltar que, dependendo do tipo de cana a ser cortada haverá variações nestes procedimentos. Não é possível o corte simultâneo de vários colmos quando esta se encontra "deitada" ou "acamada". Em tal situação os colmos devem ser cortados individualmente, implicando em maior desgaste e menor produtividade da força de trabalho.

O modo de ser do trabalho no corte da cana é marcado por um ritmo acelerado, tendo em vista que deve estar perfeitamente articulado com as exigências de matéria prima para a industrialização do açúcar e do álcool. O corte da cana é apenas uma parte de um processo industrial altamente organizado, demandando todo um preparo logístico.

Durante toda a jornada o trabalhador repetirá exaustivamente os mesmos gestos. Abraçar o feixe de cana, curvar-se, golpear com o podão a base dos colmos, levantar o feixe, girar e empilhar a cana nos montes. Essa seqüência contínua de movimentos torna o trabalho repetitivo, monótono, automatizado. Tais movimentos, conjugados com a exposição às inclemências meteorológicas e às inerentes a própria atividade, levam o trabalhador a diminuir seu limiar de atenção, aumentando a possibilidade de ocorrência de acidentes, seja com o próprio podão assim como por picadas de animais peçonhentos. E não são só os acidentes que determinam processos de morbidade e/ou mortalidade dos trabalhos rurais. Seu corpo, utilizado como parte das engrenagens da indústria sucroalcooleira, rapidamente se desgasta e sofre. São comuns as queixas de dores na coluna vertebral, principalmente lombar e torácica, assim como dores de cabeça.

Embora a base técnica do processo de trabalho no corte da cana-de-açúcar apresente si- 
milaridades em seu modo de ser com as de outras regiões canavieiras do país, são expressivas as particularidades regionais quando se considera o seu modo de organização e o enfrentamento das adversidades desta forma concreta de trabalho.

Os trabalhadores, inseridos no processo de trabalho do corte da cana, estão submetidos a outras categorias de trabalhadores, a saber: os feitores, ou empreiteiros/agenciadores de mãode-obra, responsáveis por sua arregimentação, transporte e fiscalização direta do trabalho da turma, pelo controle da qualidade do trabalho, freqüência diária e número de horas que permanecem na lavoura; os frentistas (ou fiscais), que são funcionários da usina (ou destilaria) responsáveis pela fiscalização geral da frente de trabalho - compostas pelas várias turmas; os baseadores (ou entregadores), responsáveis pela medição e pela queima da cana.

No que tange às relações sociais de trabalho observa-se, na região, uma heterogeneidade. O instrumento regulamentador destas relações é a Convenção Coletiva de Trabalho firmada, por um lado, pela classe patronal, representada pelo Sindicato da Indústria do Açúcar do Estado de São Paulo e pelo Sindicato da Indústria de Fabricação do Álcool do Estado de São Paulo e, por outro, pela Federação dos Trabalhadores na Agricultura no Estado de São Paulo (FETAESP). Nem sempre tem sido possível iniciar a safra do corte da cana-de-açúcar, com um acordo coletivo de trabalho já firmado, pois são comuns as situações de impasse nas negociações que antecedem o início de cada safra, sendo necessário, em alguns casos, a intermediação da Justiça do Trabalho. Quando isto ocorre, a safra se inicia sob o manto legal do acordo firmado na safra anterior.

Ocorrem na região, basicamente dois tipos de relações contratuais: o contrato estabelecido diretamente entre o trabalhador e a usina (ou destilaria) e o contrato intermediado pelos empreiteiros de mão-de-obra, antigamente designados por "gatos", que hoje se estabeleceram, juridicamente, na forma de empresas prestadoras de serviços de trabalhos temporários.

A remuneração do trabalhador é definida por um conjunto de mecanismos previstos no Acordo Coletivo da categoria, sendo bastante heterogênea. De forma geral, o trabalhador recebe por tonelada de cana cortada. No final da safra, quando ocorre o corte das canas de qualidade inferior, diminuindo a produtividade do trabalhador, a forma de remuneração é alterada, e ele passa a receber um salário fixo.

Quando o contrato de trabalho é por produção, a remuneração deve ser acrescida de uma hora do salário-dia, com o adicional de $50 \%$ referente ao salário in itineri.

Ao final da safra, quando há pouca cana disponível para o corte ou existem apenas canas de qualidade inferior, o trabalhador passa a receber um salário fixo, acrescido de $50 \%$ do preço da jornada normal de trabalho quando a hora in itineri não consta nas 8 horas normais de jornada. Em tais períodos, os trabalhadores ocupam-se principalmente da capina, plantio e aplicação de agrotóxicos.

De forma geral, um trabalhador corta, aproximadamente, 8 toneladas/dia (6 toneladas/ dia no caso do trabalhador do sexo feminino). Alguns trabalhadores, entretanto, conseguem atingir a marca das 14 toneladas/dia (10 toneladas/dia no caso do trabalhador do sexo feminino). A produtividade varia dependendo do tipo de cana disponível para o corte. As "canas em pé”, cultivadas em terrenos regulares, são as que propiciam maior produtividade que, logicamente é menor quando a cana encontra-se "acamada" e cultivada em terrenos irregulares.

Considerando as diferenças acima apontadas, o valor a ser pago pelo corte da cana deve ser previamente comunicado aos trabalhadores, conforme determinação do Acordo Coletivo de Trabalho da categoria. Segundo este instrumento, tal comunicação deve ser feita, no máximo, até o final de sua jornada de trabalho. Essa regra, entretanto, vêm sendo sistematicamente desrespeitada na região.

Com esta prática e devido ao fato de a medição da cana cortada ser realizada pelos feitores, baseadores ou entregadores, o trabalhador, via de regra, perde o controle sobre o seu trabalho.

A medição da cana cortada é feita com um instrumento, composto por duas réguas de madeira, com extremidades de ferro, distantes 2 metros entre si, denominado compasso. Com este intrumento, os feitores, baseadores ou entregadores medem quantos metros lineares o trabalhador cortou no eito, convertendo, através de um fator, os metros cortados em toneladas cortadas.

A cana utilizada como amostra para o cálculo do fator é obtida através da média de, no mínimo, três amostragens/talhão cortados. $\mathrm{O}$ Acordo Coletivo de Trabalho da categoria prevê que tal metodologia seja aplicada às vistas dos trabalhadores, o que, via de regra, não ocorre.

O conjunto de funções desempenhadas pelos intermediários de mão-de-obra, destacando-se as figuras dos feitores, baseadores e fiscais da lavoura nos permite compreender como se processa o controle sobre a força de trabalho, não só no âmbito do espaço da produ- 
ção, mas também no âmbito de seu espaço reprodutivo.

No tocante ao espaço da produção, as atividades e atitudes dos feitores e baseadores tem implicações diretas na remuneração de cada trabalhador. Segundo Alessi \& Scopinho (1994), enquanto este recebe por sua produtividade ou pela diária integral, aqueles controlam um conjunto de fatores que interferem diretamente no seu ganho. Estes fatores variam desde a indicação do local e tipo de cana para o trabalhador cortar; a escolha da cana a ser pesada e que servirá como amostra; a decisão sobre o número de horas diárias que o trabalhador permaneceu na lavoura e a expedição do cartão individual de produtividade.

Tais autoras alertam, ainda, para o fato de que, apesar da Convenção Coletiva de Trabalho prescrever, numa de suas cláusulas, que o cartão de produtividade deva ser entregue ao término de cada jornada diária de trabalho, os trabalhadores recebem dos feitores o referido cartão com um ou mais dias de atraso.

Este fato, relacionado “(...) ao não conhecimento diário do preço da cana cortada acaba retirando do trabalhador uma das poucas possibilidades de exercer algum controle sobre o resultado de seu próprio trabalho. Na realidade, o recebimento dos 'pirulitos' com atraso impossibilita aos trabalhadores reviverem, na memória, o eito e o tipo de cana que cortaram" (Alessi \& Scopinho, 1994).

É possível também pensar no controle exercido pelos intermediários de mão-de-obra fora do espaço reprodutivo, na medida em que cabe a eles a decisão de quem deve ou não ser transportado até o local de trabalho.

"Esse conjunto de atividades centradas nas figuras dos intermediários de mão-de-obra, feitores, baseadores e fiscais da lavoura, configuram padrões de relações de controle, impondo ritmos acelerados ao trabalho..." (Alessi \& Scopinho, 1994).

As formas como essas relações sociais se conjugam têm dificultado algumas tentativas formais ou informais de mobilização/organização intentadas por estes trabalhadores. Os sindicatos dos trabalhadores, por um lado, tentam fazer cumprir os acordos coletivos, tendo como alvo, os feitores e/ou os supervisores da lavoura. Os empresários do setor, por sua vez, interferem nas atividades dos sindicatos, promovendo um constante rodízio de seus agenciadores, dificultando o estabelecimento de vínculos mais estreitos entre os agenciadores e os trabalhadores.

A esse modo de ser do trabalho do corte da cana-de-açúcar, seu modo de divisão e organi- zação social corresponde um conjunto de cargas laborais que irão se traduzir em padrões de desgaste biopsíquicos dos trabalhadores do corte da cana-de-açúcar.

Tais trabalhadores, conforme mencionado anteriormente, se expõem, diariamente, a cargas físicas, químicas e biológicas, que se traduzem em uma série de doenças, traumas ou acidentes a elas relacionadas, tais como dermatites, conjuntivites, desidratação, cãimbras, dispnéia, infecções respiratórias, oscilações da pressão arterial, ferimentos e outros acidentes (inclusive os de trajeto). Além destas cargas laborais, devemos destacar aquelas de caráter biopsíquicos, que configuram padrões de desgaste manifestos através de dores na coluna vertebral, dores torácicas, lombares, de cabeça e tensão nervosa (stress), além de outros tipos de manifestações psicossomáticas que podem se traduzir, principalmente, por quadros de úlcera, hipertensão e alcoolismo.

\section{Considerações finais}

Dada a complexidade da temática Saúde e Trabalho Rural, a possibilidade de compor um quadro geral das questões relacionadas à saúde do trabalhador rural no país não prescinde da análise de processos de trabalho concretos.

Nesse sentido é que se buscou recompor o processo de trabalho do cortador de cana para apreender os padrões de desgaste e reprodução a que está submetida a força de trabalho ocupada nessa atividade, na região nordeste do Estado de São Paulo.

Cabe destacar algumas das transformações que vêm ocorrendo no setor canavieiro, objeto de análise desse trabalho, e que, em última instância, contribuem para agravar ainda mais o quadro que foi exposto, tendo implicações direta nas condições de vida, trabalho e saúde dos trabalhadores rurais da cultura canavieira. Uma dessas transformações diz respeito ao uso abusivo do trabalho de crianças e adolescentes nesta atividade.

Segundo estimativa do Ministério Público, esta força de trabalho corresponde a $2,5 \%$ da mão-de-obra empregada na região, no ano-safra de 1995, sendo que correspondia a $5 \%$ e $10 \%$ respectivamente, nos anos-safra de $1994 \mathrm{e}$ 1993.

O emprego da mão-de-obra infanto-juvenil no país é expressivo, sendo significativa a sua absorção nas atividades rurais, destacando-se, entre outros, o trabalho na carvoaria, na colheita de laranja e algodão, no corte da canade-açúcar e na cultura do rami (Navarro, 1991). 
O diretor para o Brasil da OIT (Organização Internacional do Trabalho) João C. Alexim, apresentou no 4o Fórum Empresarial Sobre Trabalho Infantil, realizado no Rio de Janeiro em julho de 1995, dados que apontam o setor agropecuário brasileiro como sendo o que mais utiliza esta mão-de-obra. "Com base em dados de 1990, 42,9\% das crianças e adolescentes que trabalham estão empregados no setor agrícola" (Scofield Jr., 1995).

É grande a polêmica em torno dessa questão. Por um lado, presencia-se na região uma campanha da qual participam várias entidades de movimentos sociais organizados, que é coordenada por setores do Ministério Público que procura coibir a utilização da força de trabalho infanto-juvenil em atividades sabidamente penosas e insalubres, cuja proibição é prevista no Capítulo V do Estatuto da Criança e do Adolescente. Por outro lado, coloca-se a necessidade de milhares de famílias recorrerem ao ingresso prematuro no mercado de trabalho de seus filhos menores de idade, como fonte de complementação da renda familiar.

Estas crianças e adolescentes, ao se submeterem ao desempenho de atividades penosas e insalubres, estão sendo expostas, cotidianamente a acidentes de trabalho que podem materializar-se em lesões irreversíveis, a doenças do trabalho, que podem comprometer seu desenvolvimento físico, psicológico e social.

Outro aspecto que precisa ser destacado, refere-se a transformações que vêm ocorrendo na base técnica do processo de trabalho da cultura da cana-de-açúcar. A sua mecanização desde a fase do plantio até o corte vem se acentuando nos últimos anos, materializando cada vez mais o "fantasma do desemprego" de expressivos contingentes de trabalhadores rurais.

A redução do número de postos de trabalho tem sido significativa, sendo que o corte da cana, para uma única usina da região, na safra 1989/90 foi realizado por 13.000 podões e, na safra 1991/92 a introdução de colhedeira resultou na redução deste número para, aproximadamente, 2.700 podões (Scopinho, 1995).

Segundo estimativas do Instituto de Economia Agrícola de São Paulo (I.E.A.), a mecanização do corte de cana-de-açúcar poderá desempregar cerca de 119 mil trabalhadores na região de Ribeirão Preto até o ano 2.000, (cada colhedeira substitui cerca de 60 trabalhadores). De acordo com esse estudo, esta estimativa implica uma taxa anual de desemprego crescendo de $18 \%$ a $55 \%$, em uma área mecanizável correspondente a $60 \%$ do total da região. Segundo o mesmo Instituto, o corte da cana queimada emprega hoje, mais de 40 mil trabalhadores na região, que produz em média 56 milhões de toneladas de cana-de-açúcar (Pereira, 1994).

Pode-se afirmar que a mecanização do corte da cana-de-açúcar agrava ainda mais as condições de vida, trabalho e de saúde dos trabalhadores que se dedicam a essa atividade. Considerando que as lavouras sujeitas à mecanização são aquelas situadas em áreas de solo regular, onde a cana se encontra em pé e, portanto, onde o trabalhador consegue maior produtividade, ao trabalhador restará o corte da cana de áreas irregulares, e/ou da cana "deitada" ou "emaranhada", onde as condições de trabalho são mais adversas e a produtividade do trabalho é baixa.

Tais transformações em curso colocam como padrões de desgaste-reprodução emergentes do processo de trabalho do cortador de cana-de-açúcar as conseqüências do ingresso precoce da criança e do adolescente no mercado de trabalho e o desemprego. Estes padrões não constituem, necessariamente, especificidade dessa categoria de trabalhadores quando se consideram as transformações que vêm se processando no mundo do trabalho na contemporaneidade, com contornos mais acentuados nos países pobres. 


\section{Referências}

ALESSI, N. P. \& PINHEIRO, S. A., 1987. Caracterização Sócio - Econômica da Região de Ribeirão Preto. Ribeirão Preto: Faculdade de Medicina de Ribeirão Preto, Universidade de São Paulo. (mimeo.)

ALESSI, N. P. \& SCOPINHO, R. A., 1994. A saúde do trabalhador da cana de açúcar. In: Saúde e Trabalho no Sistema Único de Saúde (N. P. Alessi; A. Palocci Filho; S. A. Pinheiro; R. A. Scopinho \& G. B. Silva, orgs.). pp. 121-151, São Paulo: Hucitec.

AMSTALDEN, L. F. \& COSTA, M. S. O., 1992. Evolução da Agricultura no Estado de São Paulo. Campinas: Associação Brasileira de Reforma Agrária.

BARRETO, M. L. \& CARMO, E. H., 1994. Situação de saúde da população brasileira: tendências históricas, determinantes e implicações para as políticas de saúde. Informe Epidemiológico do SUS, 3:7-34.

BRANDÃO, C. R., 1985. Repensando a Pesquisa Participante. São Paulo: Brasiliense.

IBGE (Fundação Instituto Brasileiro de Geografia e Estatística), 1993. Anuário Estatístico do Brasil1993. Rio de Janeiro: IBGE.

COHN, A. \& MARSIGLIA, R. G., 1993. Processo e organização do trabalho. In: Isto É Trabalho de Gente?: Vida, Doença e Trabalho no Brasil. (L. E. Rocha; R. M. Rigotto \& Buschinelli, J. T. P., orgs.), pp. 56-75. Petrópolis: Vozes.

DIAS, J. C. P., 1992. Doença de Chagas no Brasil: situação atual e perspectivas. Informe Epidemiológico do SUS, 4:17-25.

FISCHER, R. M., 1985. Pondo os pingos nos is: sobre as relações de trabalho e políticas de administração de recursos humanos. In: Processo e Relações do Trabalho no Brasil (M. T. L. Fleury \& R. M. Fischer, orgs.), pp 19-50. São Paulo: Atlas.

GONZALES, E. N. \& BASTOS, M. I., 1982. O trabalho volante na agricultura brasileira. In: A Mão-deObra Volante na Agricultura (Departamento de Economia Rural, Faculdade de Ciências Agronômicas, Campus de Botucatu, Universidade Estadual Paulista, org.), pp.35-55. São Paulo: Livraria e Editora Polis Ltda.

GRAZIANO DA SILVA, J., 1981. Progresso Técnico e Relações de Trabalho na Agricultura. São Paulo: Hucitec.

IANNI, O., 1984. Origens Agrárias do Estado Brasileiro. São Paulo: Brasiliense.

LAURELL, A. C. \& MARQUÉZ, M., 1983. El Desgaste Obrero En México. Processo De Producción Y Salud. México: Edciones Era.

LAURELL, A. C. \& NORIEGA, M., 1987. Trabajo y Salud en Sicartsa. México: Gráfica de La Universidad Autónoma Metropolitana-Xochimilco.

LAURELL, A. C. \& NORIEGA, M., 1989. Processo de Produção e Saúde. Trabalho e Desgaste Operário. São Paulo: Hucitec.

LITIVOC, J., 1985. Doença de Chagas e Estrutura Social: Infestação Domiciliar e Infecção Humana em Áreas Submetidas a Ações de Controle. Tese de Doutorado, São Paulo: Faculdade de Medicina, Universidade de São Paulo.
MARINHO, E. U. A. \& KIRCHKOFF, V. W. J. H., 1991. Projeto fogo: um experimento para avaliar efeitos das queimadas de cana-de-açúcar na baixa atmosfera. Revista Brasileira de Geofísica, 9:107119.

MARTINS, J. S., 1995. A reprodução do capital na frente pioneira e o renascimento da escravidão no Brasil. Revista de Sociologia da USP, 6:1-26.

NAVARRO, V. L., 1991. Violência do Trabalho: Condições de Vida e Trabalho dos Trabalhadores do Rami em Uraí - PR. Dissertação de Mestrado, Araraquara: Faculdade de Ciências e Letras, Universidade Estadual Paulista "Júlio de Mesquita Filho".

PAIXÃO, M. J. P., 1994. No Coração do Canavial: Estudo Crítico da Evolução do Complexo Agroindustrial Sucroalcooleiro e das Relações de Trabalho na Lavoura Canavieira. Dissertação de Mestrado, Rio de Janeiro: Programa de Engenharia de Produção. Universidade Federal do Rio de Janeiro.

PEREIRA, S., 1994. Estudo prevê desemprego por mecanização. Folha de São Paulo, 6/11, Folha Nordeste:7-2.

POSSAS, C. A. \& TRAPÉ. A. Z., 1983. Saúde e trabalho no campo: da questão agrária à política previdenciária. Cadernos do Internato Rural, 2:13-19.

POSSAS, C. A., 1989. Epidemiologia e Sociedade: $\mathrm{He}$ terogeneidade Estrutural e Saúde no Brasil. São Paulo: Hucitec.

SEADE (Fundação Sistema Estadual de Análise de Dados), 1988. Características Gerais do Processo de Industrialização Paulista. São Paulo: SEADE.

SEADE (Fundação Sistema Estadual de Análise de Dados), 1992. O Novo Retrato de São Paulo: Avaliação dos Primeiros Resultados do Censo Demográfico de 1991. São Paulo: SEADE.

SCOFIELD JR., G., 1995. Mais de 7,9 milhões de jovens trabalham no país. O Estado de São Paulo: 5/7, B-6.

SCOPINHO, R. A., 1995. Pedagogia Empresarial de Controle do Trabalho e Saúde do Trabalhador: o Caso de uma Usina-Destilaria da Região de Ribeirão Preto. Dissertação de Mestrado, São Carlos: Centro de Educação e Ciências Humanas, Universidade Federal de São Carlos.

SEMEGHINI, V. C., 1992. A região administrativa de Ribeirão Preto. In: Cenários da Urbanização Paulista - Regiões Administrativas. (Fundação Sistema Estadual de Análise de Dados, ed.), Coleção São Paulo no Limiar do Século XXI: vol. 7. São Paulo: SEADE.

SILVA, A. P. S.; BALDIN, L. S. A.; SCOPINHO, R. A. \& ALESSI, N. P., 1994. O Transporte dos Trabalhadores Rurais: A situação de um grupo após a Ocorrência de um Acidente de Trajeto. In: Saúde e Trabalho no Sistema Único de Saúde (N. P. Alessi; A. Palocci Filho; S. A. Pinheiro; R. A. Scopinho; G. B. Silva, orgs.), pp. 153-167, São Paulo: HUCITEC.

SZMRECSÁNYI, T., 1994. Tecnologia e degradação ambiental: o caso da agroindústria canavieira no Estado de São Paulo. Informações Econômicas, 24:73-81. 